\title{
Arterial Oxygenation and Management of Hypoxemia During VATS
}

\author{
Abigail M. Walsh $\cdot$ Jens Lohser
}

Published online: 4 February 2014

(C) Springer Science + Business Media New York 2014

\begin{abstract}
The volume and complexity of thoracic procedures performed with a thoracoscopic approach are steadily increasing. Surgical exposure is paramount for thoracoscopic procedures and requires meticulous lung isolation. In this review, the physiological adaptive mechanisms that occur during one-lung ventilation (OLV) are discussed. Factors that predict the occurrence of hypoxemia during OLV and a structured approach to the treatment of hypoxemia are outlined. Hypoxemia management is formulated in an escalating fashion, from basic solutions to common problems, all the way to advanced manipulations of shunt fraction and partial ventilation techniques.
\end{abstract}

Keywords Hypoxemia - Thoracoscopy · VATS . One-lung ventilation · Thoracic surgery · Thoracic anesthesiology $\cdot$ Lung isolation · Hypoxic pulmonary vasoconstriction · Oxygenation $\cdot$ Shunt $\cdot$ Cerebral desaturation $\cdot$ Protective ventilation

\section{Introduction}

Thoracoscopy was first described over a century ago, but its use surged in the 1990s following developments in

\author{
A. M. Walsh \\ Fellow in Cardiac Anesthesiology, Vancouver General Hospital, \\ JPP2 Room 2449, 899 West 12th Ave, Vancouver, \\ BC V5Z 1M9, Canada \\ e-mail: abigail.walsh@vch.ca \\ J. Lohser ( $\square)$ \\ Department of Anesthesiology, Pharmacology and Therapeutics, \\ Vancouver General Hospital, University of British Columbia, \\ JPP2 Room 2449, 899 West 12th Ave, Vancouver, \\ BC V5Z 1M9, Canada \\ e-mail: jens.lohser@vch.ca
}

fibreoptic technology and minimally invasive surgical techniques. Video-assisted thoracoscopic surgery (VATS) approaches have since been described for all types of thoracic procedures [1]. At present, there is a high rate of adoption of VATS lobectomies in academic institutions in the USA [2]. The reported clinical benefits of VATS procedures include a reduction in intraoperative blood loss, hospital length of stay, duration of chest tube drainage and postoperative pain [3•, 4]. Early concerns about oncological outcomes after lobectomies are being allayed by recent results suggesting VATS to be equivalent if not superior to open approaches [3•].

There are key differences in the anesthetic considerations between thoracotomy and VATS approaches. The thoracic cavity remains partially closed during thoracoscopic surgery, as surgical ports and instruments in effect seal the incision sites. This is the main reason for the slower lung collapse that is typical of thoracoscopic surgery. $\mathrm{CO}_{2}$ insufflation into the closed thoracic cavity to improve visualization may therefore also result in tamponade physiology [5]. Optimum surgical exposure with meticulous lung isolation is key to successful VATS. The dependence on lung isolation is in contrast to open thoracotomy procedures, where it is desirable but not essential, and substantially impacts the approach to managing hypoxemia for VATS, as partial lung re-inflation is relatively contraindicated considering its impact on surgical exposure [6].

\section{Incidence and Prediction of Hypoxemia During Thoracoscopic Surgery}

Hypoxemia during one-lung ventilation (OLV) is now occurring in about $5 \%$ of cases when defined as a decrease in arterial oxygen saturation to less than $90 \%[7,8 \bullet \bullet, 9]$, 
which is a dramatic decrease from a reported $27 \%$ in the 1970s [10]. More reliable lung isolation due to routine bronchoscopy and the lesser effects of the newer volatile anesthetics on hypoxic pulmonary vasoconstriction (HPV) are felt to be responsible for this change [6].

A number of patient and procedural factors have been described that are predictive of OLV hypoxemia [11, 12]. Increased perfusion of the operative lung predictably increases the shunt fraction during OLV and therefore the risk of hypoxemia. This explains the increased risk of desaturation with right-sided surgery and procedures after contralateral resections [13]. Similarly, supine positioning prevents gravity redistribution of pulmonary blood flow resulting in increased shunt flow [13]. Perfusion abnormalities can be determined preoperatively with ventilationperfusion (V/Q) scanning or intraoperatively by determining the end-tidal $\mathrm{CO}_{2}$ gradient between the lungs in the lateral position [14]. Moreover, intrapulmonary admixture of venous blood is increased by insufficient oxygenation of blood in atelectatic and poorly ventilated regions of the dependent ventilated lung [15].

Normal lung function tests, in particular a normal $\mathrm{FEV}_{1}$, indicate a higher risk for desaturation. This is felt to be due to the high elastic recoil in normal lung tissue, which predisposes to lung collapse in the ventilated lung. In contrast, intrinsic PEEP in the patient with obstructive lung disease is likely to be protective against atelectasis formation in both the ventilated and non-ventilated lung [6]. Assuming homogenous lung disease, poor arterial oxygenation during two-lung ventilation (TLV) is predictive of hypoxemia during OLV [6]. Conversely, significant unilateral pathology or tumor load in the operative lung may be protective, as perfusion has already been shifted toward the contralateral non-operative lung $[9,16]$.

\section{Oxygenation During One-Lung Ventilation}

Adequate oxygenation during OLV is dependent on optimal ventilation of the non-operative lung and minimizing the shunt through the operative lung. Modifiable factors influencing these will be discussed in turn.

The shunt fraction during OLV is estimated to be in the order of 20-30\% of the cardiac output [13]. In the absence of HPV, the non-ventilated lung would receive half of the pulmonary blood flow during OLV, resulting in a shunt fraction of $50 \%$ and an oxygen saturation below $90 \%$. HPV is a physiological mechanism that optimizes V/Q matching in the normal and diseased lung. During OLV, HPV minimizes the shunt fraction by restricting blood flow to the operative lung. HPV is a core principle in the understanding of oxygenation during OLV. The concept that alveolar hypoxia causes pulmonary vasoconstriction was first acknowledged about a century ago [17••]. HPV occurs throughout the pulmonary vasculature including capillaries, venules and non-muscular arterioles; however, the main site appears to be the pulmonary arterioles $[15$, 18]. Mitochondria of the pulmonary artery smooth muscle cell, which produce reactive oxygen species in response to hypoxemia, are thought to be the primary sensor for HPV [16]. The precise transduction pathway remains to be fully elucidated. HPV is a triphasic response [19, 20], with initial rapid vasoconstriction that is maximal at $15-30 \mathrm{~min}$. This is followed by gradual sustained vasoconstriction at $30-120 \mathrm{~min}$. Finally, there is a further increase when the period of regional hypoxia extends beyond $120 \mathrm{~min}$. In animal studies the threshold $\mathrm{pAO}_{2}\left(\right.$ alveolar $\mathrm{p}_{2}$ ) for the onset of HPV is approximately $80 \mathrm{mmHg}$ [21], while the maximal response is reached at a $\mathrm{pAO}_{2}$ of $25 \mathrm{mmHg}$.

Anesthesiologists control several factors that will impact the HPV response. Volatile anesthetic agents are known to inhibit HPV; however, the impact is minimal at less than 1 MAC and negligible with newer agents [22]. A recent Cochrane review of intravenous versus inhalational anesthesia for OLV concluded that there was very little evidence from randomized controlled trials to suggest differences in patient outcomes between groups [23•]. However, given that oxygenation is equivalent at low MAC values and volatiles demonstrate anti-inflammatory benefits during OLV [24•], intravenous anesthesia is likely rarely warranted.

Cardiac output needs to be maintained for adequate oxygenation because of the negative effect of low mixed venous oxygen tensions on oxygen delivery in the setting of high shunt fractions. Supra-normal cardiac output is detrimental because of inhibition of HPV by any of increased pulmonary artery pressures, increased mixed venous oxygen tensions or directly by adrenergic agents $[25,26]$.

Whether arterial oxygenation is the most appropriate monitor to judge oxygen delivery has recently been called into question by studies demonstrating cerebral oxygen desaturations in the absence of arterial hypoxemia [27]. In particular, the suggestion of a potential association with postoperative complications is concerning [28], but further research is required to define the underlying mechanism and delineate its significance.

The ventilator management of patients during OLV has changed significantly because of the realization that OLV predisposes patients to acute lung injury (ALI) in the ventilated lung [6]. Protective OLV is well established and consists of low-tidal volumes (4-6 ml $/ \mathrm{kg}$ ), routine PEEP, lower $\mathrm{FiO}_{2}$ and permissive hypercapnea $\left(\mathrm{paCO}_{2} 40-60 \mathrm{mmHg}\right)$. While beneficial from an ALI prevention perspective, there is some controversy as to whether this approach may predispose to more hypoxemia [29, 30]. Large tidal volumes 
produce more tidal recruitment than small tidal volumes [31••], which is the reason that tidal volumes of $10 \mathrm{ml} / \mathrm{kg}$ were traditionally recommended for OLV to optimize oxygenation [32]. However, the increased tidal recruitment is likely responsible for the increased lung injury seen with high tidal volumes. Given the reduced amount of tidal recruitment with protective ventilation, optimal PEEP selection is crucial to prevent atelectasis formation.

\section{Management of Hypoxemia During VATS}

OLV hypoxemia requires a structured assessment and treatment approach (Fig. 1). The urgency of the situation will vary depending on the degree of hypoxemia and patient risk factors. Increasing the $\mathrm{FiO}_{2}$ is a simple and effective maneuver that should be employed early, as it affords more time to search for the cause of hypoxemia. The single most effective way to improve oxygenation is to resume TLV. Except for the most peripheral lung lesions, however, this will completely obscure the surgical field and make surgery impossible. If the situation allows, other management steps should therefore be considered first, unless the hypoxemia is severe and resulting in end-organ dysfunction (e.g., myocardial ischemia). Dislodgement of the airway device, be it a double-lumen tube (DLT) or bronchial blocker, must be ruled out early in the course of management. Aside from direct visualization with a fiberoptic bronchoscope, changes in ventilation pressure and volume measurements may be helpful in making this diagnosis. Lung de-recruitment is common and may be due to a multitude of reasons, including hypoventilation,

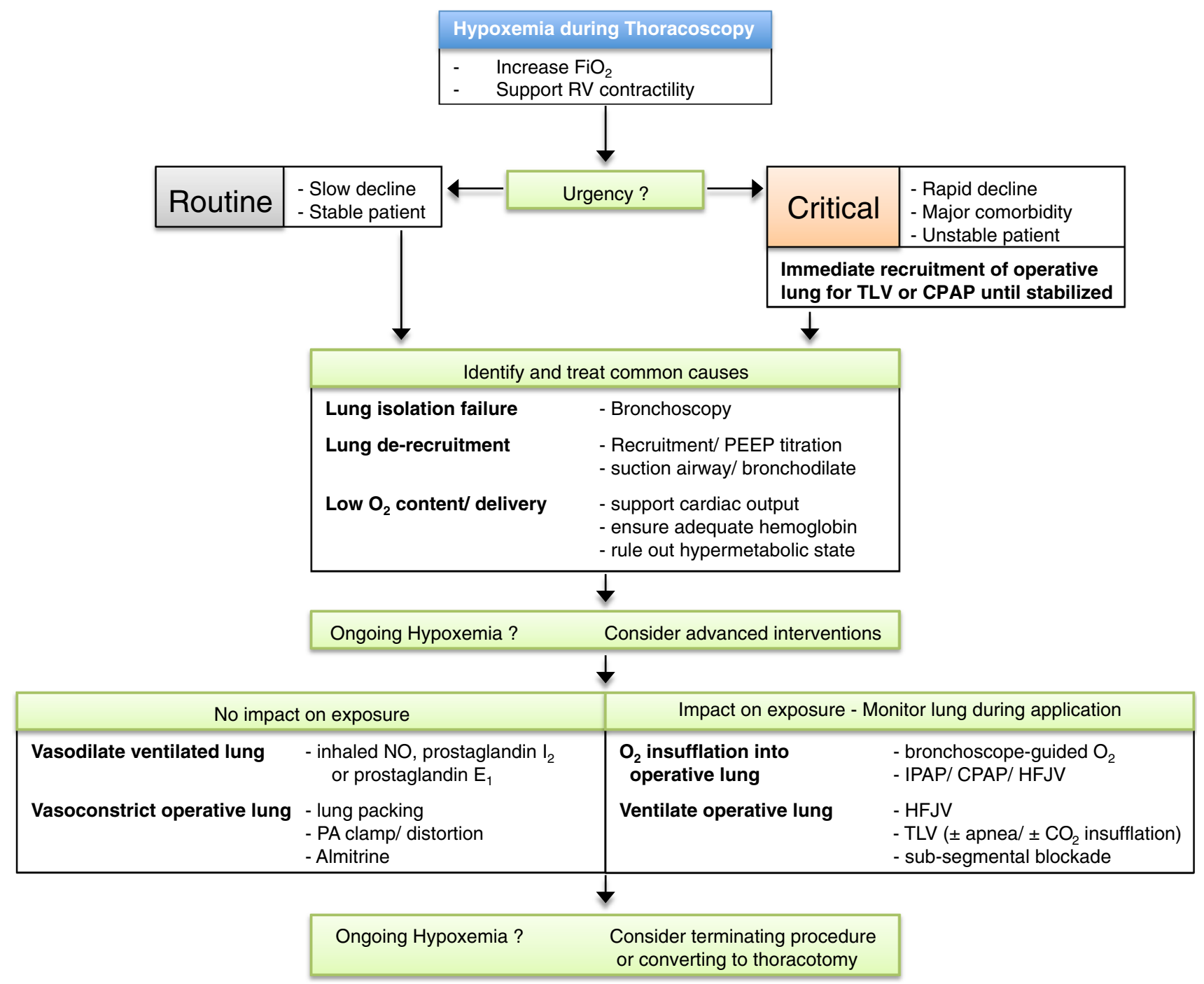

Fig. 1 OLV hypoxemia treatment pathway adapted to thoracoscopic surgery. See text for details. $\mathrm{FiO}_{2}$ fractional inspired oxygen, $\mathrm{CPAP}$ continuous positive airway pressure, $T L V$ two-lung ventilation, IPAP intermittent positive airway pressure, $N O$ nitric oxide, $P E E P$ positive end-expiratory pressure, $R V$ right ventricular, $H F J V$ high-frequency jet ventilation. Modified from [11], with permission from Elsevier 
inadequate PEEP or bronchial obstruction from airway malposition, blood or secretions. Early use of bronchoscopy will confirm patency of the airway and bronchus. Derecruitment of the ventilated lung is common, but easily correctable with lung recruitment. Recruitment maneuvers have been shown to result in marked improvements in oxygenation and ventilation. Both vital capacity maneuvers (30-40 $\mathrm{cmH}_{2} \mathrm{O}$ for 10-40 s) and cycling maneuvers with stepwise increases in Ppeak and PEEP have been reported [33]. If successful in recruiting lung, as evidenced by improved oxygenation, a recruitment maneuver should be followed by an increase in the PEEP applied.

Low cardiac output is detrimental to oxygenation because of the reduction of mixed venous oxygen content, which is harder to overcome in the setting of a high shunt fraction. Treatment should be directed at the most likely culprit, whether it is hypovolemia, sympathectomy or myocardial depression. Adrenergic agents (e.g., ephedrine, norepinephrine) will increase cardiac index and oxygen delivery, and have a beneficial effect on the pulmonary to systemic pressure ratio in patients with pre-existing pulmonary hypertension, which is in contrast to vasoconstrictors (e.g., phenylephrine) [34]. Fluid should be used sparingly so as not to contribute to postoperative ALI [35]. Blood transfusions will rarely be necessary, but can be considered in cases of symptomatic anemia. If hypoxemia persists despite optimal perfusion and ventilation of the dependent lung, advanced interventions will have to be considered.

The shunt fraction is the biggest determinant of oxygenation during OLV. Interventions that increase pulmonary blood flow in the ventilated lung, and therefore decrease the shunt through the operative lung, may therefore significantly improve oxygenation. The pulmonary vasculature has a large capacity for recruitment [36]. Selective vasodilatation of the pulmonary vascular bed in the ventilated lung can be achieved with inhalational agents. Inhaled nitric oxide (iNO), alprostadil (PGE1) and prostacyclin (PGI2, also known as epoprostenol or Flo$\operatorname{lan}^{\circledR}$ ) have all been studied in the setting of OLV. Nitric oxide diffuses rapidly across the alveolar-capillary membrane into the pulmonary vascular smooth muscle, where it activates guanylate cyclase and increases intracellular concentrations of cGMP, resulting in smooth muscle relaxation [37]. In addition to its pulmonary vasodilating effects, inhaled NO also has bronchodilating and antiinflammatory effects $[38,39]$. At doses of $20-40 \mathrm{ppm}$, it has been demonstrated to cause a significant reduction in pulmonary arterial pressure [40] and improved oxygenation in patients with pulmonary hypertension and severe hypoxemia undergoing OLV [41]. Prostacyclin has been shown to be an effective alternative in inducing pulmonary vasodilatation $[42,43]$. Alprostadil has also been shown to reduce pulmonary vascular resistance and improve oxygenation in patients undergoing lung transplantation [44]. All of these agents are expensive and require specialized delivery systems, meaning that none of them can be considered a readily available treatment for hypoxemia. They rather represent an advanced intervention in the anticipated borderline patient.

Potentiating HPV in the operative lung may further reduce the shunt fraction. Almitrine, a respiratory stimulant, acts as a selective pulmonary vasoconstrictor and has been demonstrated to increase HPV and decrease the shunt fraction [6]. An intravenous infusion of $8 \mu \mathrm{g} / \mathrm{kg} / \mathrm{min}$ of almitrine has been shown to significantly improve oxygenation during OLV, while the combination of almitrine and iNO was found to have even more profound effects on oxygenation [45]. Unfortunately, almitrine is not commercially available in North America and its safety in patients with pulmonary hypertension not fully established. In a small trial, phenylephrine was shown to have some ability in strengthening HPV, however only in half of all patients and always associated with systemic vasoconstriction [46]. Mechanical restriction of pulmonary blood flow is also a possibility. Clamping of the operative pulmonary artery has been described during VATS surgery $[47,48]$. If hilar exposure is not available, physical distortion of the lung anatomy can reduce pulmonary blood flow, but may be associated with decreases in the cardiac index because of increased right ventricular afterload [49]. Caution must therefore be exercised depending on the baseline right ventricular function and the hemodynamic response to PA manipulation.

Partial ventilation of the operative lung, or apneic oxygenation with continuous positive airway pressure (CPAP), is highly effective in improving oxygenation as it converts the shunt to lung tissue participating in gas exchange. Success of this technique requires alveolar recruitment, as application of oxygen to completely collapsed lung tissue does not improve oxygenation [50]. While being highly effective in improving oxygenation and commonly used during thoracotomy procedures, lung recruitment and CPAP are considered contraindicated during VATS surgery because of their negative impact on surgical exposure [6]. However, there is evidence that CPAP can be used during thoracoscopy. CPAP of $2 \mathrm{cmH}_{2} \mathrm{O}$ following a recruitment maneuver to the operative lung during thoracoscopy resulted in a significant improvement in oxygenation, with only a minimal decrease in surgical exposure and surgeon satisfaction scores of nine out of ten [51••]. While recruitment is essential for any CPAP technique, it clearly has to be restricted to only partial recruitment and therefore should be guided by real-time visual inspection of the lung on the surgical monitors. Modified techniques for the application of CPAP have been described. These 
include intermittent positive airway pressure (IPAP) of the operative lung, applied to either the entire lung [52] or a subsegment [53]. Application of IPAP to the entire operative lung has been described by attaching oxygen tubing with flows of $21 / \mathrm{min}$ to a bacteriostatic filter on the nonventilated lumen of the DLT, with intermittent occlusion of the filter delivering short oxygen bursts. Subsegmental IPAP has been described by positioning the tip of the fiberoptic bronchoscope into a broncho-pulmonary segment distal to the site of surgery. With the oxygen source attached to the suction port, oxygen can be delivered upon depressing the suction trigger while observing the targeted subsegment on the monitors to avoid impaired surgical exposure and over-distention. On rare occasions, ventilation of a lobe of the operative lung may be possible by selective lobar bronchial blockade using a bronchial blocker [54]. Lastly, high-frequency jet ventilation (HFJV) of the operative lung is known to be a highly effective CPAP alternative; however, it has also been anecdotally described as an alternative to lung isolation for operative lung ventilation during VATS with minimal impact on surgical exposure [55•]. Another option to consider, in consultation with the surgeon, is institution of TLV with concomitant $\mathrm{CO}_{2}$ insufflation to protect surgical exposure. As previously stated, this comes with the caveats that due to the moving lung it is more suited to peripheral or nonlung surgery and that tamponade physiology is likely.

Should intractable hypoxemia persist despite intervention, conversion to an open thoracotomy should be considered as it allows for more aggressive application of CPAP, IPAP and partial ventilation techniques.

\section{Conclusion}

There has been a large increase in the volume of thoracoscopic cases performed in the last decade. While hypoxemia has become less frequent, its management is more difficult during VATS procedures. All of the interventions known to improve oxygenation during OLV can be applied with some adjustments in technique. Partial ventilation or oxygen insufflation techniques require delicate application and good communication with the surgical team to minimize the impact on surgical exposure.

\section{Compliance with Ethics Guidelines}

Conflict of Interest Abigail M. Walsh and Jens Lohser declare that they have no conflict of interest.

Human and Animal Rights and Informed Consent This article does not contain any studies with human or animal subjects performed by any of the authors.

\section{References}

Papers of particular interest, published recently, have been highlighted as:

- Of importance

- Of major importance

1. Lee P, Mathur PN, Colt HG. Advances in thoracoscopy: 100 years since Jacobaeus. Respiration. 2010;79(3):177-86.

2. Cooke DT, Wisner DH. Who performs complex non-cardiac thoracic surgery in United States academic medical centers? Ann Thorac Surg. 2012;94(4):1060-4.

3. - Chen FF, Zhang D, Wang YL, Xiong B. Video-assisted thoracoscopic surgery lobectomy versus open lobectomy in patients with clinical stage I non-small cell lung cancer: a meta-analysis. Eur J Surg Oncol. 2013;39(9):957-63. Meta-analysis demonstrating improved surgical and oncologic outcomes with VATS lobectomies over open approaches.

4. Zhong C, Yao F, Zhao H. Clinical outcomes of thoracoscopic lobectomy for patients with clinical N0 and pathologic N2 nonsmall cell lung cancer. Ann Thorac Surg. 2013;95(3):987-92.

5. Brock H, Rieger R, Gabriel C, Pölz W, Moosbauer W, Necek S. Haemodynamic changes during thoracoscopic surgery: the effects of one-lung ventilation compared with carbon dioxide insufflation. Anaesthesia. 2000;55(1):10-6.

6. Lohser J. Evidence-based management of one-lung ventilation. Anesthesiol Clin. 2008;26(2):241-72.

7. Guenoun T, Journois D, Silleran-Chassany J, Frappier J, D'attellis N, Salem A, Safran D. Prediction of arterial oxygenation during one-lung ventilation: analysis of preoperative and intraoperative variables. J Cardiothorac Vasc Anesth. 2004;16:199-203.

8. • Yang M, Ahn HJ, Kim K, Kim JA, Yi CA, Kim MJ, Kim HJ. Does a protective ventilation strategy reduce the risk of pulmonary complications after lung cancer surgery?: a randomized controlled trial. Chest. 2011;139(3):530-7. Prospective randomized control trial demonstrating that protective OLV achieves lower but adequate oxygenation intraoperatively while producing significantly less lung dysfunction postoperatively.

9. Schwarzkopf K, Klein U, Schreiber T, Preussetaler NP, Bloos F, Helfritsch H, Sauer F, Karzai W. Oxygenation during one-lung ventilation: the effects of inhaled nitric oxide and increasing levels of inspired fraction of oxygen. Anesth Analg. 2001;92(4):842-7.

10. Tarhan S, Lundborg RO. Carlens endobronchial catheter versus regular endotracheal tube during thoracic surgery: a comparison of blood gas tensions and pulmonary shunting. Can Anaesth Soc J. 1971;18(6):594-9.

11. Lohser J. Managing hypoxemia during minimally invasive thoracic surgery. Anesthesiol Clin. 2012;30(4):683-97.

12. Slinger P, Suissa S, Triolet W. Predicting arterial oxygenation during one lung anaesthesia. Can J Anaesth. 1992;39:1030-5.

13. Karzai W, Schwarzkopf K. Hypoxemia during one-lung ventilation: prediction, prevention, and treatment. Anesthesiology. 2009;110(6):1402-11.

14. Yamamoto Y, Watanabe S, Kano T. Gradient of bronchial endtidal $\mathrm{CO}_{2}$ during two-lung ventilation in lateral decubitus position is predictive of oxygenation disorder during subsequent one-lung ventilation. J Anesth. 2009;23(2):192-7.

15. Hedenstierna G, Tokics L, Strandberg A, Lundquist H, Brismar B. Correlation of gas exchange impairment to development of atelectasis during anaesthesia and muscle paralysis. Acta Anaesthesiol Scand. 1986;30:183-91. 
16. Fike CD, Lai-Fook SJ, Bland RD. Microvascular pressures during hypoxia in isolated lungs of newborn rabbits. J Appl Physiol. 1988;65:283-7.

17. • Sylvester JT, Shimoda LA, Aaronson PI, Ward JPT. Hypoxic pulmonary vasoconstriction. Phys Rev. 2012;92(1):367. In-depth review of the entire body of research on $H P V$.

18. Toga H, Okazaki H, Ishigaki M, Noguchi T, Huang J, Fukunaga T, Nagasaka Y, Takahashi K, Ohya N. Effect of hypoxia on pulmonary blood flow-segmental vascular resistance relationship in perfused cat lungs. J Appl Physiol. 1998;84:1003-10.

19. Bennie RE, Packer CS, Powell DR, Jin N, Rhoades RA. Biphasic contractile response of pulmonary artery to hypoxia. Am $\mathbf{J}$ Physiol. 1991;261(2 Pt 1):L156-63.

20. Malik AB, Kidd BS. Time course of pulmonary vascular response to hypoxia in dogs. Am J Physiol. 1973;224:1-6.

21. Hambraeus-Jonzon K, Bindslev L, Mellgard AJ, Hedenstierna G. Hypoxic pulmonary vasoconstriction in human lungs. A stimulusresponse study. Anesthesiology. 1997;86:308-15.

22. Pruszkowski O, Dalibon N, Moutafis M, Jugan E, Law-Koune JD, Laloë PA, Fischler M. Effects of propofol vs sevoflurane on arterial oxygenation during one-lung ventilation. $\mathrm{Br} \mathrm{J}$ Anaesth. 2007;98(4):539-44.

23. - Módolo NSP, Módolo MP, Marton MA, Volpato E, Monteiro Arantes V, do Nascimento Jr P, El Dib RP. Intravenous versus inhalation anaesthesia for one-lung ventilation. Cochrane Database Syst Rev. 2013;7:CD006313. Systematic review of the literature on OLV studies fails to detect a difference in outcome associated with the type of anesthetic.

24. - Schilling T, Kozian A, Senturk M, Huth C, Reinhold A, Hedenstierna G, Hachenberg T. Effects of volatile and intravenous anesthesia on the alveolar and systemic inflammatory response in thoracic surgical patients. Anesthesiology. 2011;115(1):65-74. Randomized control trial demonstrates a reduction in proinflammatory mediators in the ventilated lung with volatile anesthetics relative to intravenous anesthesia with propofol.

25. Russell WJ, James MF. The effects on increasing cardiac output with adrenaline or isoprenaline on arterial haemoglobin oxygen saturation and shunt during one-lung ventilation. Anaesth Intensive Care. 2000;28:636-41.

26. Russell WJ, James MF. The effects on arterial haemoglobin oxygen saturation and on shunt of increasing cardiac output with dopamine or dobutamine during one-lung ventilation. Anaesth Intensive Care. 2004;32:644-8.

27. Hemmerling TM, Bluteau MC, Kazan R, Bracco D. Significant decrease of cerebral oxygen saturation during single-lung ventilation measured using absolute oximetry. Br J Anaesth. 2008;101: $870-5$.

28. Schoen J, Meyerrose J, Paarmann H, Heringlake M, Hueppe M, Berger KU. Preoperative regional cerebral oxygen saturation is a predictor of postoperative delirium in on-pump cardiac surgery patients: a prospective observational trial. Crit Care. 2011; 15:R218.

29. Montes FR, Pardo DF, Charrís H, Tellez LJ, Garzón JC, Osorio C. Comparison of two protective lung ventilatory regimes on oxygenation during one-lung ventilation: a randomized controlled trial. J Cardiothorac Surg. 2010;2(5):99.

30. Ahn HJ, Kim JA, Yang M, Shim WS, Park KJ, Lee JJ. Comparison between conventional and protective one-lung ventilation for ventilator-assisted thoracic surgery. Anaesth Intensive Care. 2012;40(5):780-8.

31. • Kozian A, Schilling T, Schütze H, Senturk M, Hachenberg T, Hedenstierna G. Ventilatory protective strategies during thoracic surgery: effects of alveolar recruitment maneuver and low-tidal volume ventilation on lung density distribution. Anesthesiology. 2011;114(5):1025-35. Animal study demonstrating increased tidal recruitment and mechanical stress with high tidal volume $O L V$, the likely culprits for the higher risk of acute lung injury.

32. Katz JA, Laverne RG, Fairley HB, Thomas AN. Pulmonary oxygen exchange during endobronchial anesthesia: effect of tidal volume and PEEP. Anesthesiology. 1982;56(3):164-71.

33. Tusman G, Böhm SH, Sipmann FS, Maisch S. Lung recruitment improves the efficiency of ventilation and gas exchange during one-lung ventilation anesthesia. Anesth Analg. 2004;98(6): 1604-9.

34. Kwak YL, Lee CS, Park YH, Hong YW. The effect of phenylephrine and norepinephrine in patients with chronic pulmonary hypertension. Anaesthesia. 2002;57:9-14.

35. Leong Chau EH, Slinger P. Perioperative fluid management for pulmonary resection surgery and esophagectomy. Semin Cardiothorac Vasc Anesth. 2013; doi:10.1177/1089253213491014.

36. Groves BM, Reeves JT, Sutton JR, Wagner PD, Cymerman A, Malconian MK, Rock PB, Young PM, Houston CS. Operation Everest II: elevated high-altitude pulmonary resistance unresponsive to oxygen. J Appl Physiol (1985). 1987;63(2):521-30.

37. Massion PB, Feron O, Dessy C, Balligand J-L. Nitric oxide and cardiac function: ten years after, and continuing. Circ Res. 2003;93:388-98.

38. Dupuy PM, Shore SA, Drazen JM, et al. Bronchodilator action of inhaled nitric oxide in guinea pigs. J Clin Invest. 1992;90:421-8.

39. Kinsella JP, Parker TA, Galan H, et al. Effects of inhaled nitric oxide on pulmonary edema and lung neutrophil accumulation in severe experimental hyaline membrane disease. Pediatr Res. 1997;41:457-63.

40. Rich GF, Lowson SM, Johns RA, Daugherty MO, Uncles DR. Inhaled nitric oxide selectively decreases pulmonary vascular resistance without impairing oxygenation during one-lung ventilation in patients undergoing cardiac surgery. Anesthesiology. 1994;80(1):57-62.

41. Rocca GD, Passariello M, Coccia C, Costa MG, Di Marco P, Venuta F, Rendina EA, Pietropaoli P. Inhaled nitric oxide administration during one-lung ventilation in patients undergoing thoracic surgery. J Cardiothorac Vasc Anesth. 2001;15(2): 218-23.

42. Haché M, Denault A, Bélisle S, Robitaille D, Couture P, Sheridan P, Pellerin M, Babin D, Noël N, Guertin MC, Martineau R, Dupuis J. Inhaled epoprostenol (prostacyclin) and pulmonary hypertension before cardiac surgery. Thorac Cardiovasc Surg. 2003;125(3):642-9.

43. Haché M, Denault AY, Bélisle S, Couture P, Babin D, Tétrault F, Guimond JG, Anaesth CJ. Inhaled prostacyclin (PGI2) is an effective addition to the treatment of pulmonary hypertension and hypoxia in the operating room and intensive care unit. Can $\mathrm{J}$ Anaesth. 2001;48(9):924-9.

44. Della Rocca G, Coccia C, Pompei L, Costa MG, Di Marco P, Pietropaoli P. Inhaled aerosolized prostaglandin E1, pulmonary hemodynamics, and oxygenation during lung transplantation. Minerva Anestesiol. 2008;74(11):627-33.

45. Paven D, Muret J, Beloucif S, Gatecel C, Kermarrec N, Guinard $\mathrm{N}$, Mateo J. Inhaled nitric oxide, almitrine infusion, or their coadministration as a treatment of severe hypoxemic focal lung lesions. Anesthesiology. 1998;89(5):1157-65.

46. Doering EB, Hanson CW, Reily DJ, Marshall C, Marshall BE. Improvement in oxygenation by phenylephrine and nitric oxide in patients with adult respiratory distress syndrome. Anesthesiology. 1997;87(1):18-25.

47. Kamiyoshihara M, Nagashima T, Ibe T, Takeyoshi I. A tip for controlling the main pulmonary artery during video-assisted thoracic major pulmonary resection: the outside-field vascular clamping technique. Interact Cardiovasc Thorac Surg. 2010; 11(5):693-5. 
48. Watanabe A, Koyanagi T, Nakashima S, Higami T. How to clamp the main pulmonary artery during video-assisted thoracoscopic surgery lobectomy. Eur J Cardiothorac Surg. 2007;31(1): 129-31.

49. Ishikawa S, Makino F, Kobinata S, Ito H, Kawano T, Makita K. Co-administration of ephedrine prevents reductions in cardiac output and systemic oxygen delivery secondary to lung compression maneuvers during one-lung ventilation, without reducing arterial oxygenation. J Anesth. 2011;25(2):163-9.

50. Slimani J, Russell WJ, Jurisevic C. An evaluation of the relative efficacy of an open airway, an oxygen reservoir and continuous positive airway pressure $5 \mathrm{~cm} \mathrm{H}_{2} \mathrm{O}$ on the non-ventilated lung. Anaesth Intensive Care. 2004;32(6):756-60.

51. • El-Tahan MR, El Ghoneimy YF, Regal MA, El Emam H. Comparative study of the non-dependent continuous positive pressure ventilation and high-frequency positive-pressure ventilation during one-lung ventilation for video-assisted thoracoscopic surgery. Interact Cardiovasc Thorac Surg. 2011;12(6):899-902. Randomized control trial of low-level CPAP or HFPPV application to the operative lung during thoracoscopic peripheral lung procedures demonstrates the feasibility of low-level CPAP for thoracoscopic procedures with minimal impedance in surgical exposure.

52. Russell WJ. Intermittent positive airway pressure to manage hypoxia during one-lung anaesthesia. Anaesth Intensive Care. 2009;37(3):432-4.

53. $\mathrm{Ku} \mathrm{CM}$, Slinger $\mathrm{P}$, Waddell TK. A novel method of treating hypoxemia during one-lung ventilation for thoracoscopic surgery. J Cardiothorac Vasc Anesth. 2009;23(6):850-2.

54. Sumitani M, Matsubara Y, Mashimo T, Takeda S. Selective lobar bronchial blockade using a double-lumen endotracheal tube and bronchial blocker. Gen Thorac Cardiovasc Surg. 2007;55(5): $225-7$.

55. - Lohser J, McLean SR. Thoracoscopic wedge resection of the lung using high-frequency jet ventilation in a post pneumonectomy patient. A\&A Case reports. 2013;1(2):39-41. Case report of HFJV use during thoracoscopic surgery provides visual (video) evidence of minimal lung movement and good surgical exposure. 